\title{
Evaluation of the Effect of Tightening Torque on Single-lap Bolted Joints
}

\author{
Djamal Boualamallah \\ Laboratory of Materials and Reactive Systems \\ University of Sidi Bel Abbes \\ Sidi Bel Abbes, Algeria \\ djamal.boualamallah@yahoo.com \\ Abdelkader Miloudi \\ Laboratory of Materials and Reactive Systems \\ University of Sidi Bel Abbes \\ Sidi Bel Abbes, Algeria \\ miloudidz@yahoo.fr
}

\author{
Abdelkader Ghazi \\ Laboratory of Materials and Reactive Systems \\ University of Sidi Bel Abbes and \\ University of Mascara \\ Algeria \\ ghaziaek@yahoo.fr \\ Mohamed Merzoug \\ Laboratory of Materials and Reactive Systems \\ University of Sidi Bel Abbes \\ Sidi Bel Abbes, Algeria \\ m_merzoug01@yahoo.fr
}

\begin{abstract}
In this experimental research, a set of tests was conducted on single-lap bolted joints in terms of choosing between two types of bolts and exploiting the optimal solution for connecting samples. Then the effect of the tightening torque on the mechanical behavior of single-lap joints was evaluated. Six simple tensile tests were performed with different values of torque and the results are reported.
\end{abstract}

Keywords-bolted assembly; mechanical behavior; experimental approach; damage mechanisms

\section{INTRODUCTION}

The construction of a structure generally involves the assembly of parts. Different assembly technologies can be used: bolting, riveting, gluing, welding, or their combinations. It is natural to assume that increasing the number of the elements that contribute to the connection increases the complexity of the structure as a whole [1]. The advantage of bolted structures is their ease of installation [2-3]. This type of connection concerns both metal sheets (aluminum, steel, etc.) and composite sheets, with aluminum or steel bolt bodies. The use of this type of structure requires the mastery of their mechanical strength. Several previous works have focused on the study of the mechanical characterization of bolted connections. These studies have focused on several aspects, including the following:

- The flexibility of the fixation.

- Load transfer.

- Stress concentrations.

- The effect of torque.

- The effect of the clearance between the bore and the body of the bolt.
- The different modes of rupture, etc.

This type of assembly has the interesting advantage of its ease of realization (drilling of holes in the plates and mounting of the fastener with or without washers). Moreover, the use of bolted assembly implies that the maintenance of a mechanical system is easier because we can repair or change the component that cannot function properly without separating all the parts of the structure. Moreover, this type of assembly makes the transport and delivery of the components easier. The bolted assembly allows minimizing the volume of finished products. Nevertheless, the presence of the bore hole is the weak point of this type of structure due to the concentration of stresses which is often the main cause of crack initiation. The dimensioning of this type of assembly must be based on numerical behavior models that allow choosing and optimizing the design parameters (dimensions), bolt and sheet (plate) properties, tightening torque, number of bolts, spacing between bolts, etc. that are optimal in terms of strength or stiffness. Difficulty also lies in determining the load transfer rate between the bolt and the plates. It is important to note that in the case of complex three-dimensional structures containing a large number of fasteners, the importance of nonlinearities (behavior, contact) would quickly lead to excessive memory and calculation time requirements [1].

Several research studies on bolted connections have addressed the influence of torque on their overall mechanical behavior under static and dynamic stresses [2]. Authors in [4] have experimentally studied the mechanical strength of a bolted composite plate connection subjected to tensile-shear stress by analyzing the effects of the diameter of the washers and the value of the tightening torque. Figure 1 shows that the increase in the tightening is accompanied by the breaking stress, but the configuration in terms of geometry of the sample is different in our research. Authors in [5] carried out a numerical simulation 
of a bolted connection of aluminum plates of thickness $\mathrm{e}=2 \mathrm{~mm}$, with three values of the tightening torque $\mathrm{Cs}=1,1.5$, and $2 \mathrm{kN}$. It was shown that the elastic load increases with the value of the tightening torque. Authors in [6] studied the caulking around the fastener. The loss of preload and its influence on stress distribution was studied in [7]. Authors in [8] studied the multi-line structure of fasteners under mechanical and thermal loading, taking into account several parameters such as clearance, friction between plates and transferred load. The analytical solution of this study is based on the principle of virtual powers. Recently, authors in [9] studied the bolted joint in uni-axial tension, using two models, the first one based on Latham and Crockoft energy, and the second one based on Gurson continuous damage. It was shown that the behavior of the structure is composed of 8 phases: linear elasticity of the material, sliding of the sheets corresponding to the bore/bolt clearance, matting phase, linear elasticity phase of the structure, plasticization phase around the substrate bores, stable and then unstable cracking phase which ends in rupture. It was found that if the tightening torque is low, the slippage appears earlier.

In the work presented in this paper, we have studied the influence of the tightening torque and the bolt material (hardened and galvanized steel) on the strength of single-lap bolted connections through experimental tests. Predicting failure mode in steel connection is a complicated task, requiring knowledge of stress distribution in the connection and understanding of different failure modes with different loading configurations. It is very difficult to model the complicated failure mechanism by analytical methods [10].

\section{MATERIAL}

The material used is galvanized steel grade H300LAD $+Z$. Figure 1 shows the elasto-plastic stress-strain curve behavior of the steel. Such materials are characterized by increased mechanical strength and the ability to resist static and shock [11].

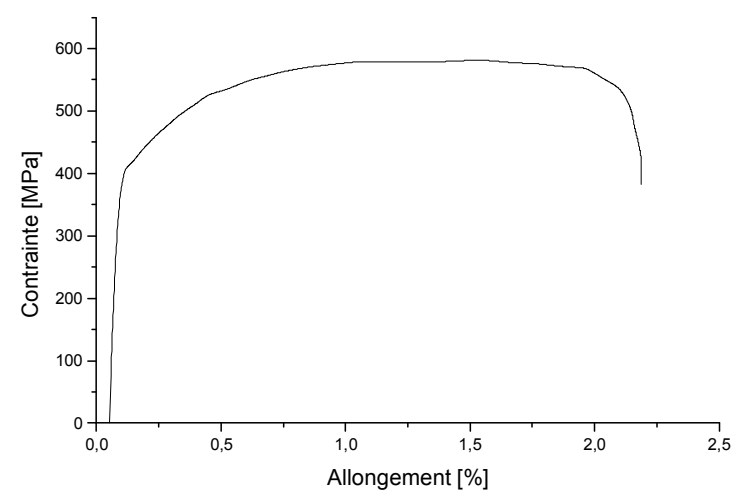

Fig. 1. Typical load-displacement curve of a specimen.

The mechanical characteristics (Table I) of the base metal such as yield strength $\sigma e$, ultimate tensile strength $\sigma \mathrm{u}$, deformation $\varepsilon$, and Young's modulus $\mathrm{E}$ were obtained from the curve in Figure 1.
TABLE I. MECHANICAL CHARACTERISTICS

\begin{tabular}{|c|c|c|c|c|}
\hline \multirow{2}{*}{$\begin{array}{c}\text { Tensile test } \\
\text { result }\end{array}$} & \multicolumn{4}{|c|}{ Characteristics } \\
\cline { 2 - 5 } & $\boldsymbol{\sigma e}[\mathbf{M P a}]$ & $\boldsymbol{\sigma u}[\mathbf{M P a}]$ & $\mathbf{E}[\mathbf{M P a}]$ & $\boldsymbol{\varepsilon}[\%]$ \\
\hline Value & 410.12 & 580.22 & 210317.9 & 0.195 \\
\hline
\end{tabular}

\section{BOLTS USED}

The type of bolts used is hexagonal head steel (Figure 2). For the bolts, the quality class is symbolized by two numbers. The first is one hundredth of the minimum tensile strength or $[\mathrm{MPa}]$ of the material and the other is 10 times the ratio between the minimum yield strength $(\sigma e)$ and the breaking strength $\mathrm{Rr}$. The first series of bolts used are made of 4.8 galvanized steel with yield strength, $\sigma e=320 \mathrm{MPa}$ and breaking strength $\sigma \mathrm{r}=400 \mathrm{MPa}$. During the tightening operation with the minimum tightening torque $(\mathrm{C}=19 \mathrm{Nm})$ the wear of the bolt threads is obtained (Figure 3 ). The second series of bolts used are made of hardened and tempered steel at $400^{\circ} \mathrm{C}$ of class 8.8 M5-20-10 (Figure 2), whose dimensions are: Nominal diameter $5.8 \mathrm{~mm}$, pitch: $0.8 \mathrm{~mm}, \sigma \mathrm{r} \approx 800 \mathrm{MPa}$, and $\sigma \mathrm{e} \approx 640 \mathrm{Mpa}$. The hexagonal nut M5 - 10, is characterized by: Minimum tensile stress $\approx 800 \mathrm{MPa}$, yield strength $\sigma \mathrm{e} \approx 640 \mathrm{MPa}$, pitch $=0.8 \mathrm{~mm}$, and thickness $=4.6 \mathrm{~mm}$. The flat washer is made of ordinary steel and has the following dimensions: Minimum diameter $=$ $6.5 \mathrm{~mm}$, maximum diameter $=12 \mathrm{~mm}$, and thickness $=1.6 \mathrm{~mm}$.

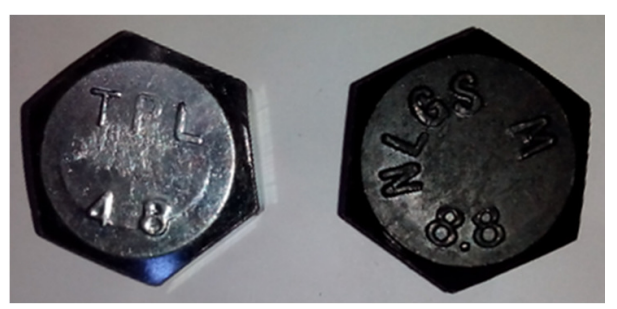

Fig. 2. Bolt symbolization.

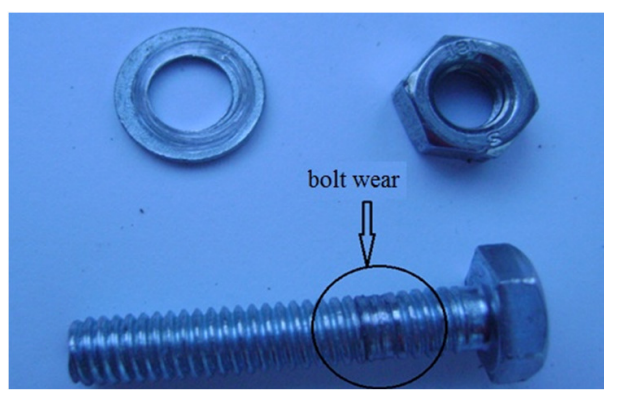

Fig. 3. Wear of the zinc-plated steel bolt (4.8)

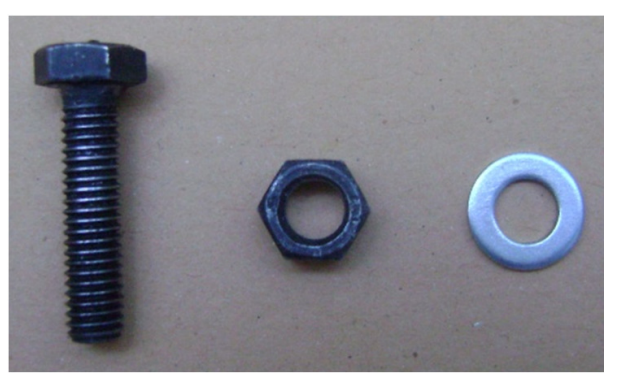

Fig. 4. Oil-hardened steel bolt. 


\section{EXPERIMENTAL PROCEDURE}

\section{A. Test Specimens and Machine}

When installing an assembly (bolt + washer + nut), it is essential to apply an appropriate tightening torque. This tightening torque is used to tension the bolt in order to keep the elements in contact. A torque wrench of ECO BUDGET brand - 19-110 NM -1/2in was used (Figure 5). The thickness of the sheet metal is $2 \mathrm{~mm}$. The types of specimens were tested as a single lap joint (Figure 5). Six values of tightening torque were used: $19,25,30,33,36$, and $39 \mathrm{~N} . \mathrm{m}$. In order to avoid the effects of friction with the nut of the bolt, a support washer was placed. The most frequently used single-bolt specimen is the Tension-Shear (TSS) specimen (Figure 6). The geometry of tensile-shear specimens is defined by $[12,13]$.

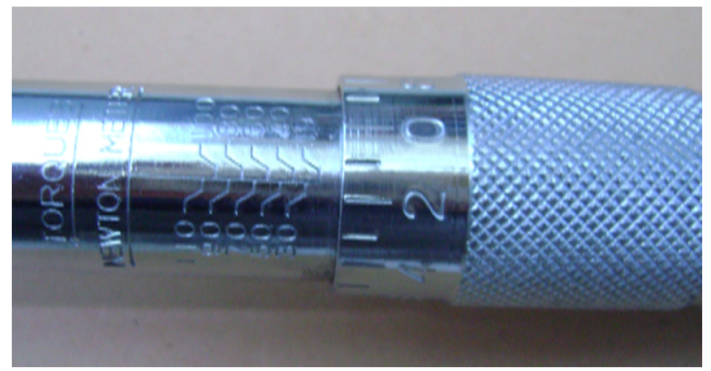

Fig. 5. Torque wrench ECO BUDGET.

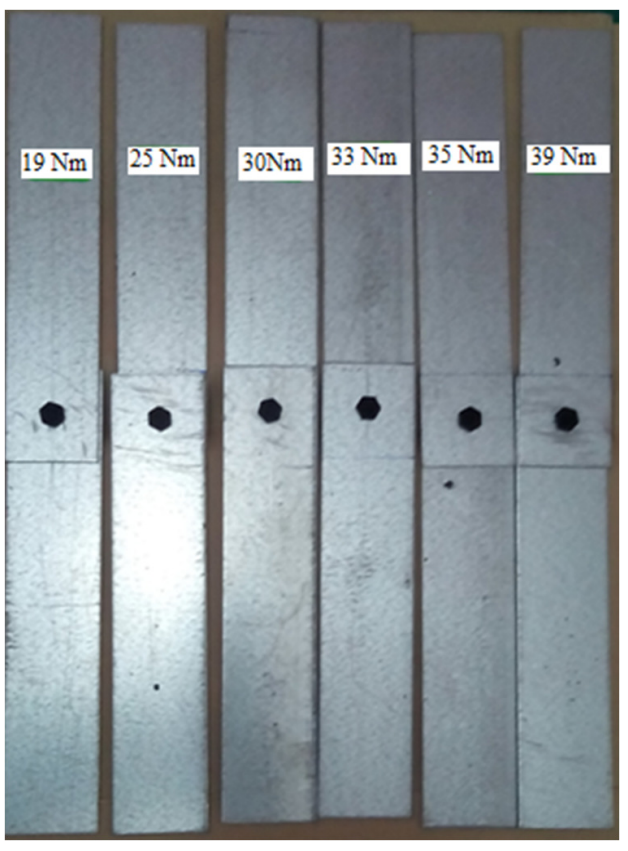

Fig. 6. The studied configurations

In this case, the bolt is stressed mainly with shear, but this stress is not pure. A bending moment is induced that tends to cause the plates to bend and deflect (Figure 7). It has been observed that the point of higher concentration of stress was in the first threads of the screw, near the screw head, whatever load was applied [14].

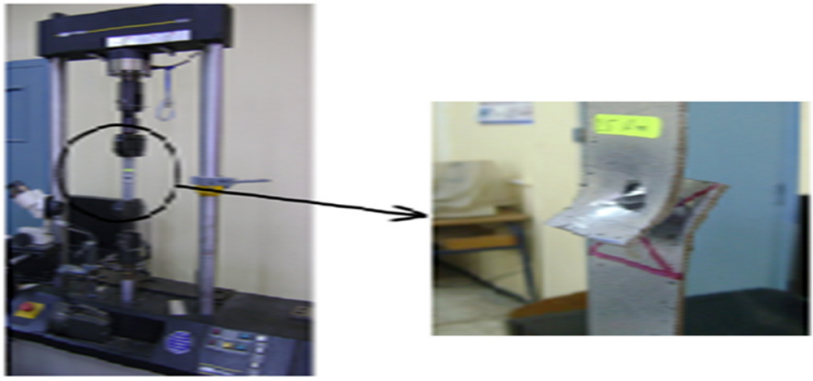

Fig. 7. Single lap joint loaded in tension-shear (sheet deformation spacing).

\section{B. Influence of Torque}

At the beginning of the tensile test of the assembly and the movement of the pieces on each other, the two influential parameters are the coefficient of friction and the torque. The first one is influenced by the surface condition and lubrication of the parts. The greater the clamping force, the greater the tensile force will be to obtain a relative displacement of the two substrates. In order to find the influence of the tightening torque, we performed tensile tests using 6 tightening torque values: $19,25,30,33,36$, and $39 \mathrm{Nm}$, on a specimen with a bolt fastening. The substrates have a bore diameter of $6 \mathrm{~mm}$ corresponding to a clearance of $0.2 \mathrm{~mm}$. The test results are presented by the load-displacement curves in Figure 8. For the high torque $\mathrm{M}=40 \mathrm{Nm}$, the thread was damaged by rotation and the high torque power which produced heat and damaged the structure (Figure 9). Figure 10 shows the maximum load that the connection can support for different torque values. We notice that the optimal results are for the tightening torques of 25 and $30 \mathrm{Nm}$. This is because the tightening torque mainly influences the elastic phase before sliding and the maximum level of load [2-17]. The tightening torque has been correctly introduced by applying local compression to the substrate and by pulling the bolt, thus allowing the prestressing forces to be introduced into the substrates [17].

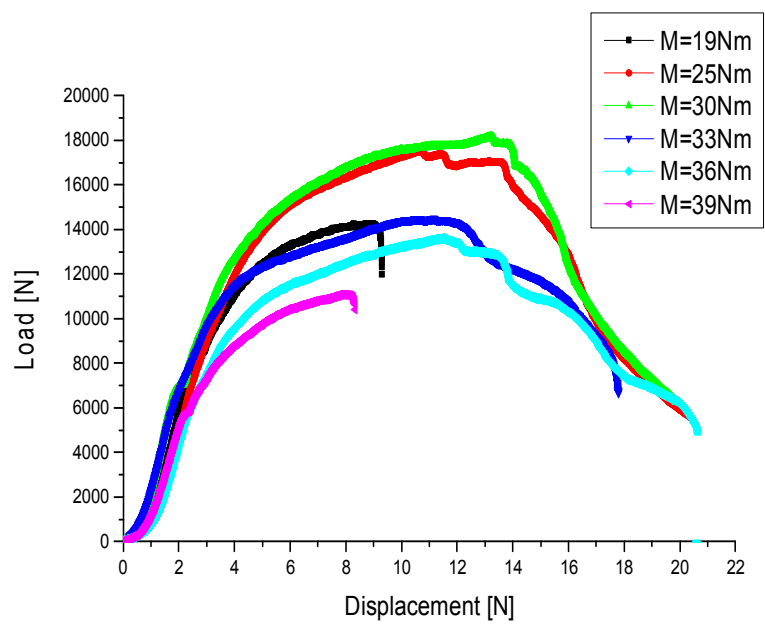

Fig. 8. Tensile curve load - displacement for 6 values of torque. 


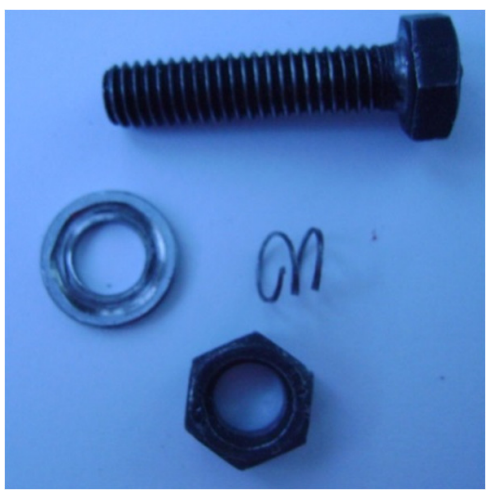

Fig. 9. Thread breakage.

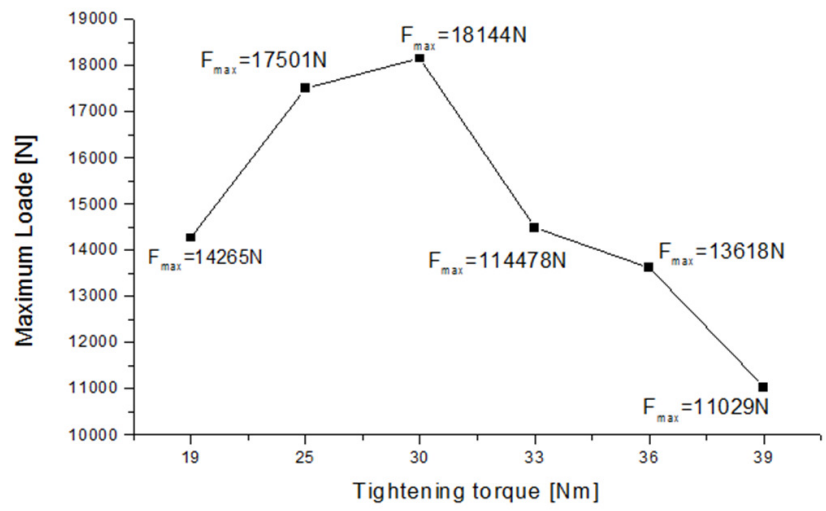

Fig. 10. Variation of maximum load vs of torque.

\section{History of the Damage Mechanism of a Bolted Assembly}

The mechanical strength of bolted connections has been the subject of several studies. Studies related to the mechanical strength in tension-shear, dynamics, fatigue, etc. can be found in the literature [2-9]. This work has been undertaken with the objective of identifying the chronology of fastener damage. Figure 11 shows the evolution of the applied load as a function of the total displacement of the structure.

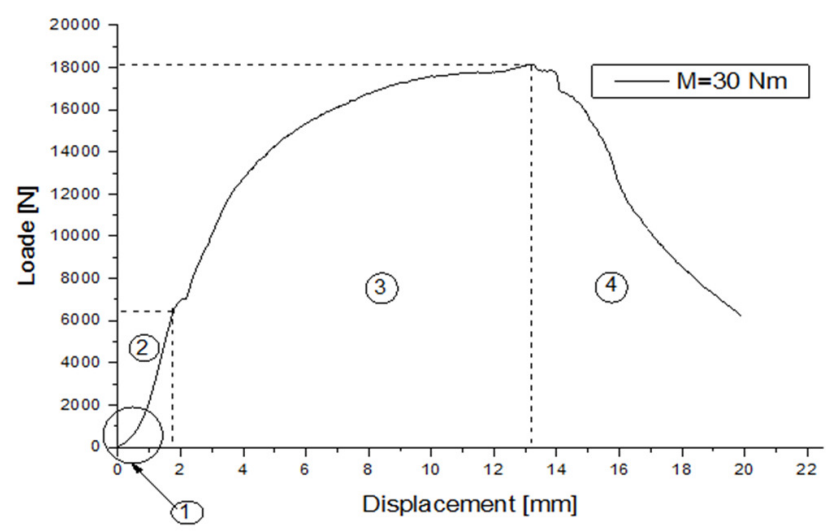

Fig. 11. Load vs displacement of a bolted assembly.

Figure 11 highlights different phases of accommodation of the connection: (1) friction and sliding of the sheets, (2) elastic transfer, (3) plastic transfer phase of secondary bending, (4) pull-out of the element and breakage of the connection. From the knowledge of the different zones it is possible to deduce the stiffness of the bolted connection $\mathrm{K}$, the elastic limit of the joint, and the breaking load.

\section{Breaking Mode and Edge Effect}

In these tensile experiments that produced a shear stress, the process was performed according to the standard and all recommended conditions for this type of test, so the results (Figure 12) were in agreement with the literature used in the field of assemblies (shear stress and peel). Figure 13 shows the failure modes for tightening torques of 19 and $39 \mathrm{Nm}$. We note that the failure occurred at the bolt, by shearing with a small displacement at the level of the structure of $5.6 \mathrm{~mm}$ for $\mathrm{M}=39 \mathrm{Nm}$ and $6.3 \mathrm{~mm}$ for $\mathrm{M}=19 \mathrm{Nm}$. The maximum torque creates torsion in the bolt diameter, which means that the bolt is damaged before the tensile test. The low value of the torque $\mathrm{M}=19 \mathrm{Nm}$ does not create the necessary adhesion for the structure [18].
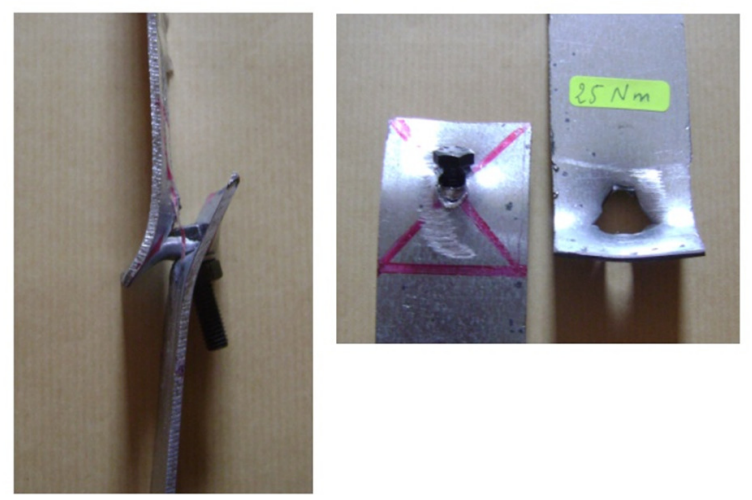

Fig. 12. Mixed tensile-shear failure mode.
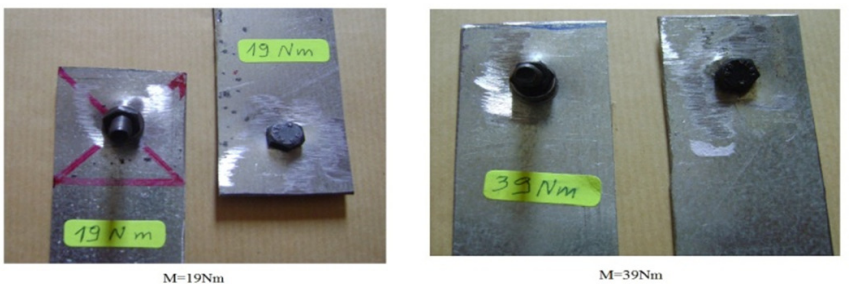

$\mathrm{M}=19 \mathrm{Nm}$

$\mathrm{M}=39 \mathrm{Nm}$

Fig. 13. Mode of rupture for $\mathrm{M}=19 \mathrm{Nm}$ and $\mathrm{M}=39 \mathrm{Nm}$.
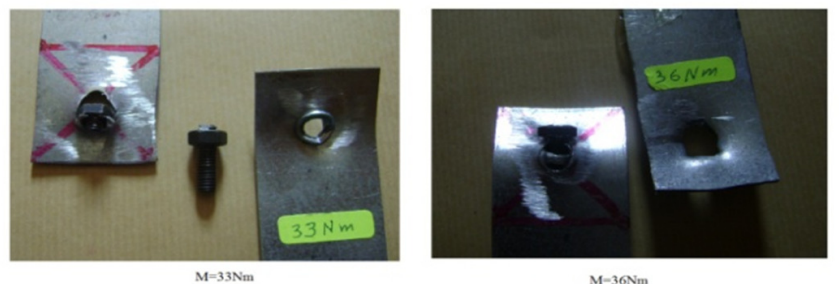

$\mathrm{M}-36 \mathrm{Nm}$

Fig. 14. Mode of rupture for $\mathrm{M}=33 \mathrm{Nm}$ and $\mathrm{M}=36 \mathrm{Nm}$.

For torques $\mathrm{M}=33 \mathrm{Nm}$ and $\mathrm{M}=36 \mathrm{Nm}$, it can be seen from Figure 14 that the strength is comparable with respect to the torque $\mathrm{M}=19 \mathrm{Nm}$, but the displacement is significant with 
respect to the latter; because the large value of the torque gives a clear adhesion between the substrates [15-19], so we have a mixed traction-shear failure mode.

For torques $\mathrm{M}=25 \mathrm{Nm}$ and $\mathrm{M}=30 \mathrm{Nm}$ it can be seen from Figure 15 that the resistance is high compared to the other torques. In this case, the mode of failure is acceptable [15-17], which means the deformation occurs at the bolt hole, and the bolt was not broken by the tensile operation.
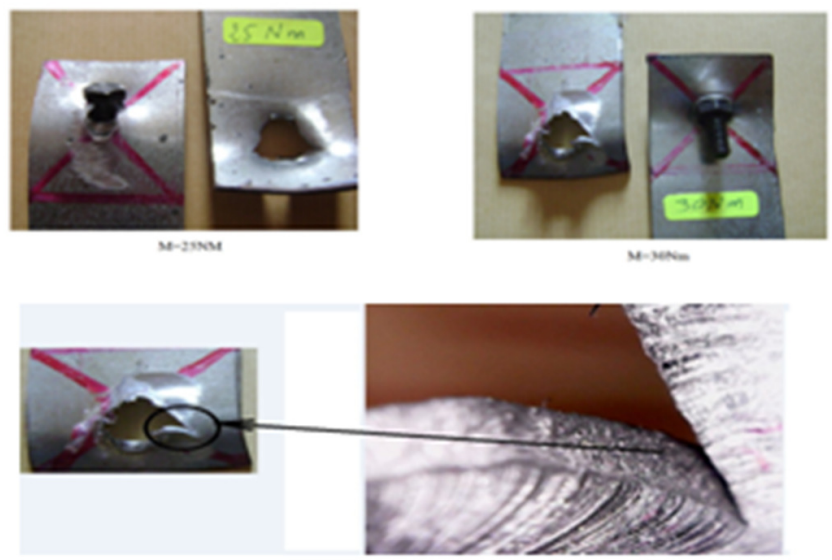

Fig. 15. Mode of rupture for $\mathrm{M}=25 \mathrm{Nm}$ and $\mathrm{M}=30 \mathrm{Nm}$.

It can be seen that the mode of failure is ductile because of the presence of the cups in the majority of the fracture surface. Figure 16 shows the failure faces of the bolts. It is noted that the failure mode is ductile because of the presence of cups in the majority of the failure surface. The fracture face (which may also be located under the head of the bolt) has a grainy appearance which may be distributed at several levels of the threaded part. There is a generally localized break on the threaded part of the bolt. This rupture follows a plastic deformation of the material.

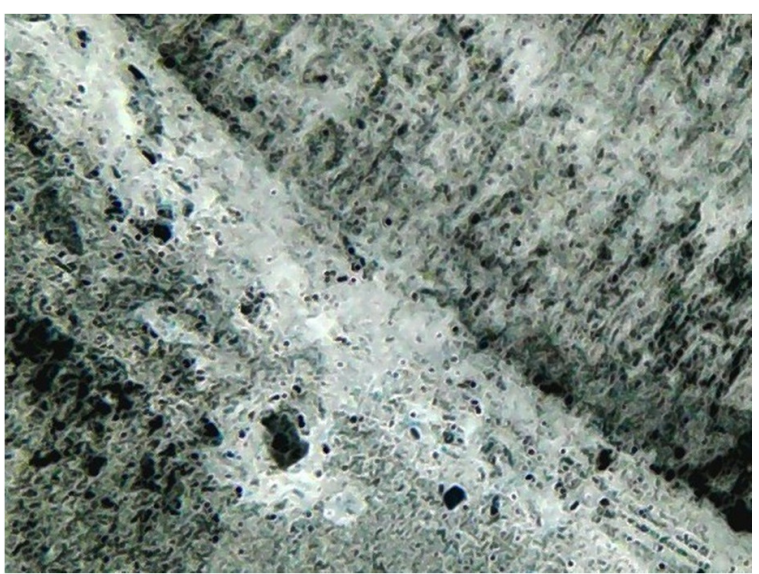

Fig. 16. Faces of bolt failure.

\section{CONCLUSION}

The indispensability of knowing the properties and mechanical characteristics of the components before any construction or assembly obliges us to always develop our instruments and means of calculation, testing and even control when it comes to the use of standardized components such as bolts. At the end of the work carried out within the framework of this article, which deals with the study of the rupture and damage of a bolted assembly made of thin sheets of thickness $\mathrm{e}=2 \mathrm{~mm}$ in galvanized steel, we conclude to the following:

- The nature of the material of the bolt has an overall influence on the behavior of the structure (type of steel).

- The correct torque for the connection extends its service life, so it the value of the torque applied to the bolt must be carefully selected, because it has an obvious impact on the modification of the behavior of the structure and thus exceeds the danger from the point of view of fracture mechanics.

\section{REFERENCES}

[1] O. Omran, "Développement d'un modèle de connecteur pour assemblage boulonné," Ph.D. dissertation, Université de Picardie Jules Verne, Amiens, France, 2015.

[2] T. Dang-Hoang, "Rupture et endommagement d'un assemblage boulonné : approche expérimentale et simulation numérique," $\mathrm{Ph} . \mathrm{D}$. dissertation, L'université de Lille, Lille, France, 2009.

[3] J. P. Muzeau, "Constructions métalliques," Techniques de l'Ingénieur, May 10, 2005. https://www.techniques-ingenieur.fr/base-documentaire/ archives-th12/archives-les-superstructures-du-batiment-tiacd/archive1/constructions-metalliques-c2521/ (accessed Dec. 24, 2021).

[4] U. A. Khashaba, H. E. M. Sallam, A. E. Al-Shorbagy, and M. A. Seif, "Effect of washer size and tightening torque on the performance of bolted joints in composite structures," Composite Structures, vol. 73, no. 3, pp. 310-317, Jun. 2006, https://doi.org/10.1016/j.compstruct.2005. 02.004 .

[5] A. D. Crocombe, R. Wang, G. Richardson, and C. I. Underwood, "Estimating the energy dissipated in a bolted spacecraft at resonance," Computers and Structures, vol. 84, no. 5-6, pp. 340-350, Jan. 2006, https://doi.org/10.1016/j.compstruc.2005.09.024.

[6] S. A. Nassar, G. C. Barber, and D. Zuo, "Bearing Friction Torque in Bolted Joints," Tribology Transactions, vol. 48, no. 1, pp. 69-75, Jan. 2005, https://doi.org/10.1080/05698190590899967.

[7] J. Yang and F.-K. Chang, "Detection of bolt loosening in C-C composite thermal protection panels: I. Diagnostic principle," Smart Materials and Structures, vol. 15, no. 2, pp. 581-590, Feb. 2006, https://doi.org/10.1088/0964-1726/15/2/041.

[8] S.-W. Yen, "Multirow joint fastener load investigation," Computers \& Structures, vol. 9, no. 5, pp. 483-488, Nov. 1978, https://doi.org/ 10.1016/0045-7949(78)90045-7.

[9] T. Dang Hoang, C. Herbelot, A. Imad, and N. Benseddiq, "Numerical modelling for prediction of ductile fracture of bolted structure under tension shear loading," Finite Elements in Analysis and Design, vol. 67, pp. 56-65, May 2013, https://doi.org/10.1016/j.finel.2012.12.003.

[10] N. Konkong, "An Investigation on the Ultimate Strength of ColdFormed Steel Bolted Connections," Engineering, Technology \& Applied Science Research, vol. 7, no. 4, pp. 1826-1832, Aug. 2017, https://doi.org/10.48084/etasr.1243.

[11] A. Buketov, O. Syzonenko, D. Kruglyj, T. Cherniavska, E. Appazov, and K. Klevtsov, "Investigation of the Influence of the Synthesized IronCarbide Mixture on the Adhesive and Mechanical Properties of Epoxy Composites for Parts of Transport Machines," Engineering, Technology \& Applied Science Research, vol. 10, no. 5, pp. 6214-6219, Oct. 2020, https://doi.org/10.48084/etasr.3750.

[12] ISO 14324:2003. Soudage par résistance - Essais destructifs des soudures - Méthode pour les essais de fatigue sur assemblages soudés par points. ISO, 2003. 
[13] Y. Xiao and T. Ishikawa, "Bearing strength and failure behavior of bolted composite joints (part II: modeling and simulation)," Composites Science and Technology, vol. 65, no. 7, pp. 1032-1043, Jun. 2005, https://doi.org/10.1016/j.compscitech.2004.12.049.

[14] S. F. Fakhouri, M. M. Shimano, C. A. Araujo, H. L. Defino, and A. C. Shimano, "Photoelastic Analysis of the Vertebral Fixation System Using Different Screws," Engineering, Technology \& Applied Science Research, vol. 2, no. 2, pp. 190-195, Apr. 2012, https://doi.org/10. 48084/etasr.144.

[15] T. Ireman, "Three-dimensional stress analysis of bolted single-lap composite joints," Composite Structures, vol. 43, no. 3, pp. 195-216, Nov. 1998, https://doi.org/10.1016/S0263-8223(98)00103-2.

[16] F. C. Campbell, Structural Composite Materials. Materials Park, OH, USA: ASM International, 2010.

[17] C. T. McCarthy, M. A. McCarthy, and V. P. Lawlor, "Progressive damage analysis of multi-bolt composite joints with variable bolt-hole clearances," Composites Part B: Engineering, vol. 36, no. 4, pp. 290 305, Jun. 2005, https://doi.org/10.1016/j.compositesb.2004.11.003.

[18] G. Kelly, "Quasi-static strength and fatigue life of hybrid (bonded/bolted) composite single-lap joints," Composite Structures, vol. 72, no. 1, pp. 119-129, Jan. 2006, https://doi.org/10.1016/j.compstruct. 2004.11.002.

[19] K. Aldas and F. Sen, "Stress analysis of hybrid joints of metal and composite plates via 3D-FEM," Indian Journal of Engineering and Materials Sciences, vol. 20, no. 2, pp. 92-100, May 2013. 